Research Article

\title{
Financial Agglomeration, Energy Efficiency, and Sustainable Development of China's Regional Economy: Evidence from Provincial Panel Data
}

\author{
Haiman Liu $\mathbb{D}$, Jiancheng Long, and Zunhuan Shen \\ School of Economics and Management, Xidian University, Xi'an 710100, China \\ Correspondence should be addressed to Haiman Liu; 19061110543@stu.xidian.edu.cn
}

Received 12 July 2021; Accepted 12 October 2021; Published 1 November 2021

Academic Editor: Jinyu Chen

Copyright (c) 2021 Haiman Liu et al. This is an open access article distributed under the Creative Commons Attribution License, which permits unrestricted use, distribution, and reproduction in any medium, provided the original work is properly cited.

\begin{abstract}
Ecological deterioration, air pollution, and resource depletion have shrouded the vast regions of China, raising widespread concerns about the sustainable development of the domestic economy. Although financial agglomeration has become a pivotal approach for China to realize green transformation, there is a lack of evidence against the causal correlation between financial agglomeration and sustainable development of the regional economy. To fill this gap, using the data of 29 provincial capital cities in China spanning from 2009 to 2019 and adopting individual time bidirectional fixed effect model, IV-GMM approach, and alternative modeling techniques, this paper investigates the impact of financial agglomeration on sustainable development of the regional economy for the first time. The results indicate that there is a significant positive correlation between financial agglomeration and the sustainable development of the regional economy. Financial agglomeration facilitates the improvement of regional energy efficiency, and the latter further mediates the relationship between financial agglomeration and sustainable development of the regional economy. In addition, the empirical results also demonstrate that the higher the economic policy uncertainty, the weaker the positive relationship between financial agglomeration and energy efficiency. The present study is of great significance for China to implement energy-saving and emission-reduction tasks and achieve sustainable urban construction.
\end{abstract}

\section{Introduction}

With increasing appeals to overcome energy shortage and environmental degradation, it is imperative for local government to continuously seek effective approaches to improve energy using efficiency, strengthen the green industry, and facilitate sustainable growth, especially for China. In China, the steady growth of GDP is accompanied by a series of enormous challenges such as global environmental turbulence, resource depletion, and ecosystem degradation. For example, in 2019, China's foreign dependence on petroleum and crude oil exceeded $70 \%$. A total of 1152 days of severe pollution occurred in 337 cities in 2020, and the days with $\mathrm{PM} 2.5, \mathrm{PM} 10$, and $\mathrm{O} 3$ as the primary pollutants accounted for $77.7 \%, 22.0 \%$, and $1.5 \%$ of the days with severe pollution and above, respectively. In this context, local government realizes that restoring nature is vital to the survival of the Earth and mankind and proposes to actively establish a green, low-carbon, and circular economic system. According to this proposal, the Chinese government pledges to strive to achieve a carbon peak by 2030 and achieve carbon neutrality by 2060 during the UN General Debate and encourages all regions to keep the economic operation within a reasonable range following the strategic deployment of the State Council while doing a good job of normalizing epidemic prevention and control. However, regional economic development is still unbalanced in China due to its vast territory and differentiated resource endowments. Therefore, considering the heterogeneity of economic development, how to enhance the sustainable development level of 
China's regional economy (RESD) has become one of the hot issues under the background of high-quality economic development.

Forming a new pattern of modern financial development in which the real economy and the financial industry promote each other and making further efforts to build a modern financial agglomeration area that meets the requirements of all-round revitalization play a fundamental role in sustainable economic development. Under China's unique institutional background, financial agglomeration is a considerable catalyst towards the low-carbon cities' sustainable development because it improves the spatial and geographic allocation efficiency of financial resources, cuts down transaction costs, and facilitates economic growth [1]. For instance, in 2017, the "Jiang Bei Zui" financial center on the upper reaches of the Yangtze River achieved a financial added value of 13.68 billion yuan, up 26.6 percent year on year. Local governments vigorously have deployed various preferential policies for financial companies such as settlement subsidies and investment subsidies. Such phenomenon is deeply rooted in the fact that, in production and consumption activities, financial agglomeration offers a "double dividend" through resource accumulation and appropriate allocation of capital in a suboptimal case [2,3]. Proponents of this view contend that financial agglomeration not only accelerates regional economic growth through diffusion and agglomeration effects [4] but also dramatically stimulates the upgrading of green industries and strengthens regional environmental protection via technical and ecological effects $[5,6]$, consequently posing opportunity and inexhaustible impetus to the sustainable development of regional economy [7].

Most studies believe that moderate financial agglomeration has greatly broadened financing channels, abated the information cost of financing, and thus stimulated technological innovation and energy conservation of enterprises at an alarming power $[6,8]$. Against the backdrop of China's advocacy of green development, financial institutions in agglomeration areas provide financial support to the upstream and downstream of the green and low-carbon industry chain, allowing the capital to lean from cumbersome and low-productivity industries to higher-productivity industries [9]. This undoubtedly eliminates backward production capacity and triggers the optimization of industrial structure, thereby indirectly heightening energy efficiency [10]. Moreover, subsidies for petroleum products are eliminated while more investment is introduced into technological innovation in an attempt to ameliorate energy efficiency as a partial approach for boosting sustainable development [11]. Research demonstrates that, in the face of increasing pressure replete with resource overexploitation and climate deterioration, improving energy efficiency injects hope for China to achieve the win-win goal of environmental protection and effective economic growth $[12,13]$. Therefore, a financial agglomeration-energy efficiency-regional economic sustainable development nexus may exist during China's economic transformation.

In addition, extensive research related to financial agglomeration relies on a stable economic policy environment.
However, China's Economic Policy Uncertainty (EPU) index did not look promising and soared from 96.9 in 2009 to 687.6 at the end of 2019, which reflects that Chinese companies wallow in the quagmire of drastic external risks. The uncertainty of economic policy constitutes a pivotal exogenous factor for China's industrial environment uncertainty because high EPU leads to higher business risks and stronger strategic defense capabilities [14]. Multiple shreds of evidence propound that high EPU has exacerbated the agency problem of companies [15], led to tactical judgment errors [16], increased the risk of technological innovation [17], and brought more carbon emissions [18]. Therefore, the uncertainty of economic policy may affect firms' energy-related innovation decisions and R\&D investment, thereby narrowing or amplifying the influence of financial agglomeration on energy efficiency.

However, the impact of financial agglomeration on the regional economy's sustainable development has been seriously neglected in existing studies. Only Cheng et al. [19] discussed the relationship between the penetration of information technology and the sustainable development of the regional economy. Empirical evidence related to financial agglomeration only concerned green development, urbanization, and marine eco-efficiency $[5,6]$. Qu et al. [10] affirmed that there was a link between financial agglomeration and energy efficiency, but scant quantitative studies have specifically investigated the relationship between energy efficiency and sustainable economic development. Hence, it is intriguing to adopt a comprehensive theoretical framework to authenticate the impact of financial agglomeration on the sustainable development of the regional economy. At the same time, what role does energy efficiency play in the relationship between financial agglomeration and the sustainable development of regional economy? How does financial agglomeration affect the regional energy practices in a high EPU environment? The resolution of these issues has important theoretical significance for China's sustainable production practice.

In order to solve the above three main problems, we first manually collect the total number of financial institutions, financial talent data, and the list of financial assets to calculate the financial agglomeration level of 29 provincial capital cities in China with an objective to reveal the relationship between financial agglomeration and the sustainable development of the regional economy. Scant research has provided insight into the catalyzing factors of regional economy's sustainable development. Upon our knowledge, our paper first addresses this gap. Secondly, unlike the existing literature which widely adopts stochastic frontier method and data envelopment analysis to assess energy efficiency, this article prefers to apply an inclusive approach, the superefficiency SBM model, to estimate energy efficiency and treats energy efficiency as a mediating variable. This not only helps to expand the research on the antecedent variables of regional economy's sustainable development but also enriches the study on the economic consequences of energy efficiency in the existing body of knowledge. Finally, scholars have pointed that considering financial agglomeration alone ignores the fundamental role of the economic 
policy environment on energy efficiency [20]. Hence, we propose a novel model leveraging economic policy uncertainty as a moderating variable to reveal the policy scenarios of financial agglomeration's influence on energy efficiency, which is a beneficial extension of the research on economic policy uncertainty.

\section{Theoretical Analysis and Research Hypothesis}

2.1. Financial Agglomeration and the Sustainable Development of Regional Economy. It is necessary to clarify the theoretical logic that financial agglomeration affects the sustainable development of a regional economy. In literature, Ye et al. [1] accentuated that financial agglomeration relies on the accumulation and allocation effects of financial capital to reinforce the city's infrastructure allocation. Financial agglomeration's active impact on green development is attributed to financial agglomeration's scale effect, technical effect, structural effect, and network effect [6]. Unfortunately, the ecological or environmental benefits induced by financial agglomeration have been largely ignored in past studies. Hence, this article attempts to reclassify the functional effects of financial agglomeration and postulates that the direction to which financial agglomeration affects the regional economy's sustainable development is primarily contingent on its economic, technical, and ecological effects.

The economic effect refers to that enterprises in a specific financial agglomeration area could increase the output ratio by obtaining scale economy effect and diffusion effect, thus driving the economic growth. From the perspective of economies of scale, financial institutions and related enterprises in financial clusters are more proactive in executing the highly relevant division of labor and collaboration to enable the quick flow of production factors such as information, capital, technology, and labor in clusters [21]. This has an inductive effect on economic growth because the agglomeration center has integrated various resources, reduced time cost, and transaction cost [1]. Concomitantly, the benefits of economies of scale can only be shared when there exists close proximity of banking, securities, and insurance industries [4]. Besides, the development of financial agglomeration drives the spillover effect of industries other than the financial industry in technological innovation, knowledge, economy, and other fields, thereby driving the coordinated development of the financial industry and other fields. Under such a premise, the flow of expertise and specialized resources raises the service level of diverse institutions and mitigates the instability of the economic environment [22].

Technological effect means that financial agglomeration becomes more relevant to boost sustainable development by stimulating technological innovation. In China, the technological effect always occurs in the financial agglomeration center [6]. The financial cluster is characterized as having a strong technological willingness and could provoke novel sophisticated products in the fields of energy science, material science, and ecological ethics [21]. Currently, China’s ecological civilization construction requires scientific and technological innovation to be unified with the goal of sustainable development, while the formation of financial agglomeration centers could just ease the credit constraints faced by enterprises and supply basic capital guarantees for potential technological innovation initiatives, such as the development of new materials and utilization of new energy [23]. Furthermore, the spatial accumulation of financial industries not only broadens the market capacity of a specific region but also intensifies the sharing of positive externalities of information overflow [24], thereby indirectly serving the production innovation.

Stimulated by financial agglomeration, firms have become more and more environmentally friendly through green development. China's financial industries inevitably shoulder the dual missions of economic development and environmental preservation, which compels financial institutions to increase the proportion of green products and ameliorate the ecological environment by adjusting the direction of resource flow [7]. For instance, in the context of the conversion of new and old kinetic energy, financial institutions dominate the flow of capital underpinning the green high-end industries, smart manufacturing industries, and clean industries, thereby releasing green dividends [25]. This has promoted the green transformation of regional industrial structures [26]. In short, the agglomeration of financial elements would change the pattern, efficiency, and benefits of traditional industries and promote the expansion of green industries, thus not only achieving the goal of pollution control but also transforming ecological advantages into economic advantages. Then, the following hypothesis is proposed.

2.1.1. Hypothesis 1. Financial agglomeration has a positive effect on the sustainable development of the regional economy.

\subsection{Financial Agglomeration and Energy Efficiency.} Technical and management indicators were advocated by scholars as the most direct and powerful drivers affecting energy efficiency $[27,28]$. For example, J. M. Simkoff et al. [28] demonstrated that the precise control of enterprise control systems achieved novel instantaneous operations such as conversion smoothing or demand response, thereby raising energy efficiency. From the perspective of metafrontier inefficiency and its decomposition, Cheng et al. [29] concluded that, less than $40 \%$ of energy inefficiency stemmed from technological gap inefficiency, and more than $60 \%$ came from management inefficiency. Therefore, the theoretical derivation of the impact of financial agglomeration on regional energy efficiency is inseparable from the perspectives of technology and management.

Firstly, financial agglomeration is a probable catalyst for the upgrading of energy-saving technologies. Financial agglomeration better responds to the financial market's demand for capital investment and depositors' liquidity preferences on their assets, realizing an effective docking between investment and financing. Financial institutions 
strictly ensure the credit scale of enterprises with serious environmental pollution, and low resource utilization is subject to certain restrictions [30]. Conversely, financial agglomeration not only furnishes sufficient financial support and long-term incentive for innovative entities aiming at developing energy technologies [31] but also provides these entities with feasible channels for risk diversification, which undoubtedly bolsters the development and diffusion of energy technology. Secondly, the agglomeration mode builds basic trust and integrity between enterprises through information sharing and business cooperation, aimed at promoting mutual exchanges among firms. Especially for energy-intensive enterprises, the potential trust constraints between organizations not only reduce the possibility of transaction defaults but also exert stringent supervision and governance over production activities of firms, which help to increase the proportion of good output [32]. Interestingly, the network synergy of financial agglomeration acts as a significant channel for enterprises to establish a platform of mutual trust. This would curb opportunistic tendencies in business management, improve governance, and raise energy efficiency. Therefore, we put forward the following assumption:

2.2.1. Hypothesis 2. Financial agglomeration has a positive effect on energy efficiency.

2.3. The Mediating Role of Energy Efficiency. Improving energy efficiency is an extremely cost-effective and readily scalable option to maintain a city's sustainable development because it could simultaneously address economic, environmental protection, and resource issues [33]. In terms of the environment, multiple benefits are obtained by improving energy efficiency. For instance, Ozbugday and Erbas [34] accentuated that, under the same scenario, a $1 \%$ increase in energy efficiency reduced carbon dioxide emissions by $0.55 \%$ in the future. Notably, the improvement of energy efficiency not only mitigates primary energy consumption, $\mathrm{CO}_{2}$ emissions, and environmental pollution but also increases energy security and expands competitiveness [35]. Hence, while encouraging sustainable economic growth, energy conversion efficiency must be enhanced to produce more work with less carbon-based energy. In addition, although energy accounts for a small share of total production costs, it is a prerequisite for social activity and economic growth. For example, the U.S. government acknowledges that energy efficiency plays as an advantageous element toward trade competition strategy. Bataille and Melton [36] concluded that improvements in energy efficiency contributed to a $2.0 \%$ increase in Canada's GDP and a $0.19 \%$ increase in macroeconomic performance between 2002 and 2012. In terms of resource utilization, high energy efficiency reduces water usage and fuel input for power plants [37], and numerous studies advocate that high energy efficiency has a positive impact on ecological optimization and resource utilization and is the primary strategy towards sustainable economic development $[3,12,38]$. Therefore, based on the logic of financial development-energy efficiency-economic performance, this paper further conjectures that energy efficiency plays an intermediary role in the correlation between financial agglomeration and the sustainable development of a regional economy. To sum up, we have the hypothesis as follows:

2.3.1. Hypothesis 3. Financial agglomeration positively influences the sustainable development of the regional economy by improving the level of energy efficiency.

\subsection{The Moderating Role of Economic Policy Uncertainty.} The normal exertion of financial agglomeration's favorable effects would be subjected to the economic policy environment. Under the background of high EPU, firms tend to exhibit retreat, evasiveness, and conservativeness when implementing the technology innovation plan. Research has indicated that, due to the nondispersibility of political risk, policy uncertainty requires equity risk premiums [39], which may affect enterprises' cost of capital [40]. The increase in the cost of capital turns a project with a positive net present value into a negative one. As a result, economic policy uncertainty leads to an increase in the cost of capital, which reduces the motivation for companies to raise funds. Raza et al. [41] elucidated that high EPU suppressed corporate investment by triggering higher energy and resource prices. Therefore, although financial agglomeration offers financial incentives for innovation subjects, high EPU inhibits corporate innovation investment and aggravates the risk of innovation projects. In addition, high EPU causes fluctuations in business expectations and managerial judgments [16]. Although financial agglomeration has weakened the opportunism of corporate management, high EPU seriously affects the firms' information environment [42], exacerbates managerial complexity [15], and even induces a decline in the proportion of $\mathrm{R} \& \mathrm{D}$ devoted to environmental expenditure [43]. In an uncertain environment, industrial firms often make up for the low turnover rate by switching to cheap energy production, which in turn undermines corporate performance and brings more carbon emissions [20]. In a nutshell, economic policy uncertainty may inhibit the smooth development and utilization of energy-saving technologies, and in turn, moderate the relationship between financial agglomeration and energy efficiency. Thus, we develop the following hypothesis.

2.4.1. Hypothesis 4. EPU negatively regulates the positive correlation between financial agglomeration and energy efficiency.

Based on the above analysis, the present paper constructs a conceptual model as follows (see Figure 1):

\section{Methodology}

3.1. Sample and Data. Since complete data on Taiwan, Xinjiang, Macao, Tibet, and Hong Kong are not available, only 29 provinces in China were comprised in the sample. In order to mitigate the special lash of the global financial crisis 


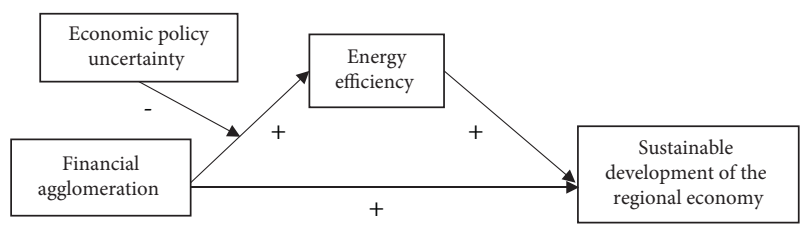

Figure 1: The conceptual model diagram.

on China's economy in 2008 and to maintain the validity and integrity of data, the sample observation time began in 2009. Therefore, this article attempted to test the impact of financial agglomeration on the regional economy's sustainable development based on the 29 provinces' panel data in mainland China over the period 2009 to 2019. The data were primarily derived from "China Energy Statistical Yearbook," "China City Statistical Yearbook," "China Environmental Statistical Yearbook," "China Information Industry Yearbook," "China Statistical Yearbook," and "Wind Financial Information Terminal." Concerning data processing, the missing data were supplemented by an interpolation method with the mean value of adjacent years, and data with different statistical units were converted during the sample sorting process. Lastly, a total of 319 observations were obtained, and the empirical analysis was carried out using STATA15.1 statistical software.

3.2. Variable Definitions. Sustainable development of the regional economy (RESD) is the dependent variable. Congruent with Cheng et al.'s [19] recommendation to address RESD, this article adopts a distinctive indicator of the sustainable development of China's regional economy which highlights three crucial subsystems of resources, environment, and economy. Combining the 22 evaluation indicators of the three subsystems with the measurement algorithm for each indicator's weight advocated by Cheng et al. [19], it is easy to engender the relatively objective and accurate RESD values for each province. Table 1 details the evaluation indicators of RESD.

Similarly, referring to the research of Cheng et al. [19], the calculation process of RESD is as follows:

(1) Build the original matrix

$$
Y=\left(y_{i, j}\right)_{\beta} \text {. }
$$

(2) Standardization:

$$
\begin{aligned}
& \text { positive index }\left(U_{i, j}\right)_{\beta}=\frac{y_{i, j}-\min \left(y_{i, j}\right)}{\max \left(y_{i, j}\right)-\min \left(y_{i, j}\right)}, \\
& \text { negative index }\left(U_{i, j}\right)_{\beta}=\frac{\max \left(y_{i, j}\right)-y_{i, j}}{\max \left(y_{i, j}\right)-\min \left(y_{i, j}\right)} .
\end{aligned}
$$

(3) Index normalization processing:

$$
\left(p_{i, j}\right)_{\beta}=\frac{\left(U_{i, j}\right)_{\beta}}{\sum_{\beta=1}^{m} \sum_{i=1}^{f}\left(U_{i, j}\right)_{\beta}} .
$$

(4) Calculate the entropy of indicators:

$$
\begin{aligned}
& E_{\beta}=-f_{1} \sum_{\beta=1}^{m} \sum_{i=1}^{f}\left(p_{i, j}\right)_{\beta} \ln \left(p_{i, j}\right)_{\beta}, \\
& f_{1}=\frac{1}{\ln (m \times f)}, \quad m=11, f=29 .
\end{aligned}
$$

(5) Calculate each indicator's weight:

$$
w_{\beta}=\frac{1-E_{\beta}}{\sum_{j=1}^{n}\left(1-E_{\beta}\right)} .
$$

(6) Calculate RESD:

$$
\operatorname{RESD}_{i, j}=\left(U_{i, j}\right)_{\beta} \times w_{\beta}
$$

$Y$ refers to the original matrix composed of a total of $\beta$ indicators in province $i$ and year $j$, and $\left(U_{i, j}\right) \beta$ denotes the standardized matrix. $\left(p_{i, j}\right) \beta$ refers to the normalization of the standardized matrix $\left(U_{i, j}\right) \beta . E_{\beta}$ represents the information entropy of the calculated $\beta$ index, while $w_{\beta}$ is the weight of each indicator. Finally, $\mathrm{RESD}_{i, j}$ signifies the sustainable development of the regional economy of $i$ province in $j$ year. Figure 2 visually plots the average index of RESD for 29 provinces from 2009 to 2019. From the perspective of comprehensive RSD value, Beijing is the province with the highest level of regional economic sustainable development, while Inner Mongolia and Qinghai have lower RSD values. On the whole, the average RESD values of many provinces are within the range of 0.3 and 0.4 , reflecting that the sustainable development situation of China's regional economy is not optimistic.

In combination with characteristics of the financial industry and industrial agglomeration, financial agglomeration (FA) is simply defined as the optimization and restructuring process of the financial industry and relevant industries, resulting in the agglomeration of information, capital, and other resources in a certain region $[1,5,10]$. Previous studies generally assess the degree of financial agglomeration from four aspects of the financial environment, financial depth, financial breadth, and financial scale $[5,6]$. Through the above theoretical discussion and literature review, this article argues that the measurement of financial agglomeration should treat the financial industry as a whole, which encompasses the expansion of financial assets, the concentration of financial institutions and entities, and the collection of financial talents. Therefore, based on the principles of accessibility and maneuverability, the present study constructs the evaluation indicators of financial agglomeration from 11 subindicators of 3 items, as shown in Table 2. In order to make the measurement of financial agglomeration reflect the actual 
TABLE 1: Evaluation index of RESD.

\begin{tabular}{|c|c|}
\hline Subsystems & Measurement index \\
\hline Resource subsystem & $\begin{array}{c}\text { Internet penetration rate, } Y_{1} \\
\text { Mobile phone penetration rate, } Y_{2} \\
\text { Proportion of e-commerce sales, } Y_{3} \\
\text { Percentage of service industry websites, } Y_{4} \\
\text { The proportion of R\&D investment, } Y_{5} \\
\text { The proportion of highly educated technical personnel, } Y_{6} \\
\text { The proportion of regional market contract transactions, } Y_{7} \\
\text { The development level of high-tech industry, } Y_{8} \\
\text { Number of companies conducting business via the internet, } Y_{9}\end{array}$ \\
\hline Economic subsystem & $\begin{array}{l}\text { The proportion of software technology industry, } Y_{10} \\
\text { The proportion of information industry employment, } Y_{11} \\
\text { Number of legal persons in the service industry, } Y_{12} \\
\text { Network strength, } Y_{13} \\
\text { R\&D and sales ratio of new products, } Y_{14} \\
\text { The degree of capital absorption of industrial enterprises, } Y_{15} \\
\text { The proportion of technological transformation of high-tech industry, } Y_{16} \\
\text { R\&D expenditure ratio of industrial enterprises to universities, } Y_{17} \\
\text { Percentage of foreign investment, } Y_{18} \\
\text { The ratio of service industry value added to GDP, } Y_{19}\end{array}$ \\
\hline Environmental subsystem & $\begin{array}{c}\text { Energy consumption, } Y_{20} \\
\text { The ratio of environmental pollution investment to GDP, } Y_{21} \\
\text { Electricity consumption, } Y_{22}\end{array}$ \\
\hline
\end{tabular}

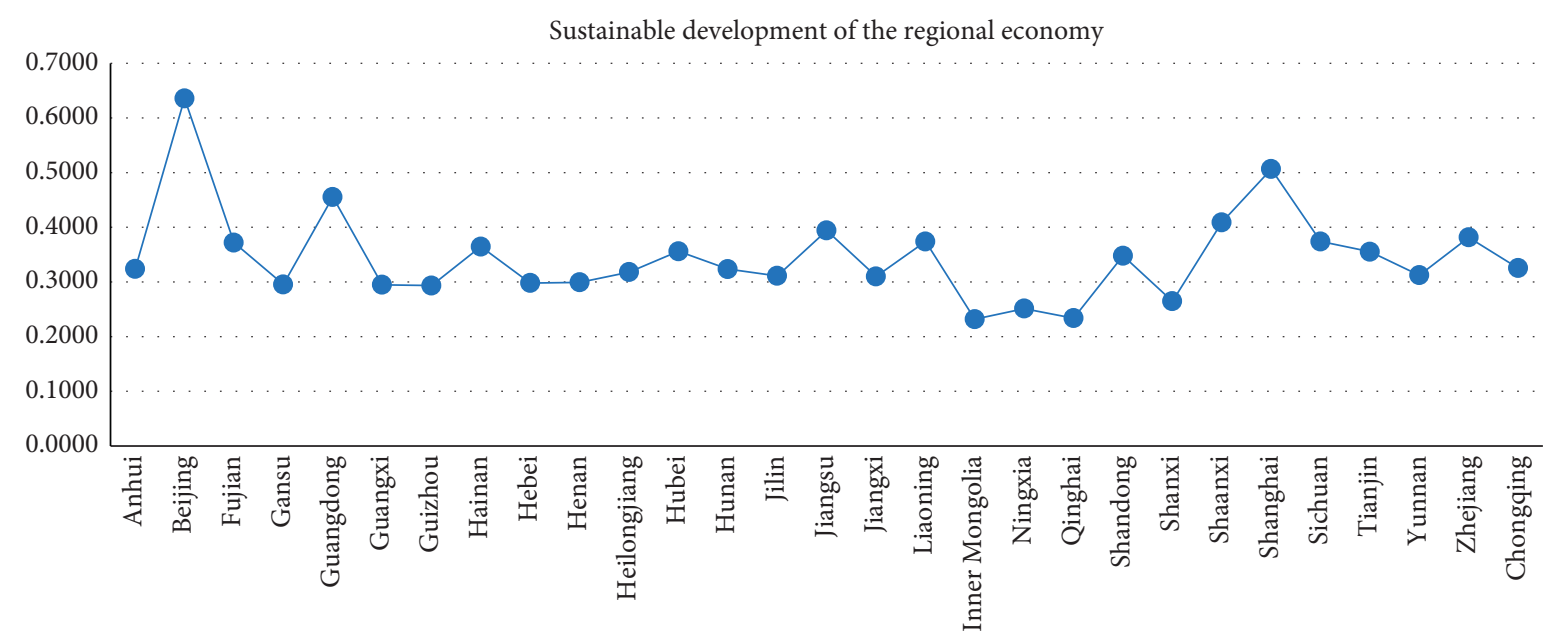

FIgure 2: The line chart of the average value of RESD for 29 provinces.

TABLE 2: Evaluation index of financial agglomeration.

\begin{tabular}{|c|c|c|}
\hline First-level indicators & Secondary indicators & Polarity \\
\hline Financial assets & $\begin{array}{c}\text { Deposit balance of financial institution, } X_{1} \\
\text { Loan balance of financial institution, } X_{2} \\
\text { Total financing for shares and bonds, } X_{3} \\
\text { Original insurance premium income, } X_{4} \\
\text { Actual utilization of foreign direct investment amount, } X_{5} \\
\text { Added value of the financial industry, } X_{6}\end{array}$ & $\begin{array}{l}+ \\
+ \\
+ \\
+ \\
+ \\
+\end{array}$ \\
\hline Financial institutions & $\begin{array}{l}\text { Number of financial institution outlets per unit area, } X_{7} \\
\text { Total number of securities, funds, and future companies headquartered in the jurisdiction, } X_{8} \\
\text { Total number of insurance companies headquartered in the jurisdiction, } X_{9} \\
\text { Total number of domestic listed companies at the end of the year, } X_{10}\end{array}$ & $\begin{array}{l}+ \\
+ \\
+ \\
+\end{array}$ \\
\hline Financial talents & $\begin{array}{c}\text { Number of employees in the financial industry, } X_{11} \\
\text { Financial employment rate, } X_{12}\end{array}$ & $\begin{array}{l}+ \\
+\end{array}$ \\
\hline
\end{tabular}


agglomeration level of each province as much as possible, the relevant measurement of financial institutions, financial assets, and financial talents includes all information within each province. For example, when measuring the deposits of financial institutions, the financial institutions here include the number of network points of all financial institutions in the provincial capital and other cities. Although the proliferation of practice adopting energy intensity to estimate energy efficiency in different cultural contexts [44], this measurement does not apply to China due to its vast territory and immense diversity in economic development between diverse provinces. Hence, the authors employ the location entropy index introduced by Qu et al. [10] that could precisely mirror the spatial distribution of China's financial agglomeration. The specific process is as follows.

(7) Build the original matrix:

$$
X=\left(x_{i, j}\right) .
$$

(8) Standardization:

Dimensionless processing of data by year to obtain standardized data year by year.

$$
x_{i, j}^{*}=\left\{\begin{array}{l}
\frac{x_{i, j}-\min \left(x_{i, j}\right)}{\max \left(x_{i, j}\right)-\min \left(x_{i, j}\right)} \text { the polarity of } x_{i, j} \text { is positive, } \\
\frac{\min \left(x_{i, j}\right)-x_{i, j}}{\max \left(x_{i, j}\right)-\min \left(x_{i, j}\right)} \text { the polarity of } x_{i, j} \text { is negative. }
\end{array}\right.
$$

(9) Contribution of indicators:

$$
p_{i, j}=\frac{x_{i, j}}{\sum_{i=1}^{29} x_{i, j}}
$$

(10) Calculate the information entropy of indicators:

$$
e_{j}=-\frac{1}{\ln (n)} \sum_{i=1}^{29} p_{i, j} \ln \left(p_{i, j}\right) \text {, and } n=29 \text {. }
$$

(11) Calculate each indicator's weight:

$$
w_{j}=\frac{1-e_{j}}{\sum_{j=1}^{n}\left(1-e_{j}\right)} .
$$

(12) Calculate the financial agglomeration level:

$$
\mathrm{FA}_{i}=\sum_{j=1}^{n} x_{i, j} \times w_{j}, \quad i=1,2,3, \ldots, 29 .
$$

$X$ refers to the original matrix composed of indicators in province $i$ and year $j . x_{i, j}^{*}$ denotes the standardized matrix gained by standardizing the original matrix. $p_{i, j}$ acts as the contribution of province $i$ to the index $j$, while $e_{j}$ means the information entropy of the indicators. $w_{j}$ implies the weight of each indicator, and $\mathrm{FA}_{i}$ signifies the financial agglomeration level of $i$ province in $j$ year.

Total-factor energy efficiency is particularly suitable for measuring energy efficiency (EFF) since it has laid great emphasis on the substitution effect of other inputs on energy and is more in line with the Pareto efficiency theory in econometrics [45, 46]. Parametric frontier analysis and nonparametric frontier analysis are two mainstream approaches for estimating total-factor energy efficiency [47]. The nonradial data envelopment analysis (DEA) approach solves the problems of undesirable output and slack variables well and has been widely touted in research [48]. However, the efficiency value calculated by the traditional nonradial DEA model ranges between 0 and 1 , and when the efficiency values of multiple decision-making units (DMUs) are efficient (that is, the efficiency value is 1 ), the difference between these DMUs cannot be further distinguished. Therefore, we follow the superefficiency SBM model advocated by Du et al. [49] and Zhang et al. [50] to make up for the defect of incomparability between multiple effective DMUs. Suppose there are $n$ decision-making units, and each DMU contains $m$ inputs, $D_{1}$ desirable outputs, and $D_{2}$ undesirable outputs. The specific vector is designed as $z \in R^{m}, w^{a} \in R^{D_{1}}$, and $w^{b} \in R^{D_{2}} . Z, W^{a}$, and $W^{b}$ are input matrix, desirable output matrix, and undesirable output matrix, respectively, where $\mathrm{Z}=\left[z_{1}, z_{2}, \ldots, z_{n}\right] \in R^{m \times n}, W^{a}=\left[w_{1}^{a}, w_{2}^{a}, \ldots, w_{n}^{a}\right] \in R^{D_{1} \times n}$, and $W^{b}=\left[w_{1}^{b}, w_{2}^{b}, \ldots, w_{n}^{b}\right] \varepsilon R^{D_{2} \times n}$. The energy efficiency value of DMU can be expressed as follows:

$$
\mathrm{EFF}^{*}=\frac{1 / m \sum_{i=1}^{m} \overline{z_{i}} / z_{i e}}{1 / D_{1}+D_{2}\left(\sum_{r=1}^{D_{1}} w_{D_{1}} / w_{D_{1} e}+\sum_{k=1}^{D_{2}} w_{D_{2}} / w_{D_{2} e}\right)},
$$

subject to

$$
\begin{aligned}
\bar{z} & \geq \sum_{j=1, \neq e}^{n} z_{j} \beta_{j}(i=1,2, \ldots, m), \\
\overline{w^{a}} & \leq \sum_{j=1, \neq e}^{n} w_{j}^{a} \beta_{j}\left(r=1,2, \ldots, D_{1}\right), \\
\overline{w^{b}} & \geq \sum_{j=1, \neq e}^{n} w_{j}^{b} \beta_{j}\left(k=1,2, \ldots, D_{2}\right), \\
\beta_{j} & \geq 0, \sum_{j=1, \neq e}^{n} \beta_{j}=1, \\
\bar{z} & \geq z_{e}(i=1,2, \ldots, m), \\
\overline{w^{a}} & \geq w_{e}^{a}\left(r=1,2, \ldots, D_{1}\right), \\
\overline{w^{b}} & \geq w_{e}^{b}\left(k=1,2, \ldots, D_{2}\right),
\end{aligned}
$$

where $\beta$ is a weight vector and $\beta_{j}$ is the weight of DMU $j$. The above nonlinear model can be transformed into a linear model by conversion of Charnes-Cooper method. EFF* is the energy efficiency value of DMU, and a larger value of

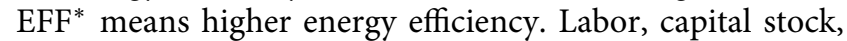
and energy consumption are the major input factors. Since 
the employees' number does not truly reflect the labor quality's difference, we use the product of the number of employees and average years of education to measure labor input. The perpetual inventory method is applied to estimate capital stock. It is feasible to use the product of GDP and energy intensity as a proxy variable for energy consumption. The ideal output is expressed in terms of the gross domestic product of each region, and carbon dioxide emissions are selected to measure undesired output.

The aggregate index advocated by Baker et al. [51] is used to compute China's EPU. The establishment of this aggregate index relies mainly on the frequency of articles in the South China Morning Post on economic policy uncertainty. The annual EPU is preliminarily estimated using the natural logarithm of the monthly mean EPU.

Moreover, this paper contains some plausible controlling variables which have been proved to be significant factors affecting regional sustainable development [10, 19]. The main control variables include R\&D input $(\mathrm{RD})$, market demand (MD), and government intervention (GI), and the specific measurement methods are expounded in Table 3.

3.3. Empirical Model. In the objective to address the influence of FA on RESD and the mediation effect of energy efficiency between the two, the paper adopts the casual step means recommended by Baron and Kenny [52]. Relevant models are designed as follows:

$$
\begin{aligned}
\mathrm{RESD}_{i, t} & =\alpha+\beta \mathrm{FA}_{i, t}+\gamma \operatorname{Control}_{i, t}+\mu_{t}+\varepsilon_{i, t}, \\
\mathrm{EFF}_{i, t} & =\alpha+\beta \mathrm{FA}_{i, t}+\gamma \operatorname{Control}_{i, t}+\mu_{t}+\varepsilon_{i, t}, \\
\mathrm{RESD}_{i, t} & =\alpha+\beta \mathrm{FA}_{i, t}+\delta \mathrm{EFF}_{i, t}+\gamma \operatorname{Control}_{i, t}+\mu_{t}+\varepsilon_{i, t},
\end{aligned}
$$

where $i$ represents province and $t$ is time. $\operatorname{RESD}_{i, t}$ means the sustainable development of regional economy in $t$ year of region $i . \mathrm{FA}_{i, t}$ indicates financial agglomeration level, and $\mathrm{EFF}_{i, t}$ is the regional energy efficiency in year $t$. Control $_{i, t}$ consists of several control variables, including R\&D input, market demand, and government intervention. $\mu_{t}$ stands for the unobservable and nonnegligible intercept term generated by individual heterogeneity, and $\varepsilon_{i, t}$ reflects the disturbance of time effect to the model.

Next, this paper verifies the moderating effect of economic policy uncertainty on the correlation between FA and EFF by constructing a moderation effect model. In equation (19), the interaction term between financial agglomeration and economic policy uncertainty is added.

$$
\begin{aligned}
\mathrm{EFF}_{i, t}= & \alpha+\beta_{1} \mathrm{FA}_{i, t}+\beta_{2} \mathrm{EPU}_{t}+\gamma \operatorname{Control}_{i, t}+\mu_{t}+\varepsilon_{i, t}, \\
\mathrm{EFF}_{i, t}= & \alpha+\beta_{1} \mathrm{FA}_{i, t}+\beta_{2} \mathrm{EPU}_{t}+\beta_{3} \mathrm{EPU}_{t} \\
& \times F A_{i, t}+\gamma \text { Control }_{i, t}+\mu_{t}+\varepsilon_{i, t},
\end{aligned}
$$

where coefficient $\beta_{3}$ is the main object of observation. If $\beta_{3}$ is significant statistically, it means that the moderating effect exists.

\section{Empirical Results}

4.1. Descriptive Statistical Analysis. Table 4 displays the descriptive statistical results of all variables. It is observed that the sustainable development level of China's regional economy is relatively low because the average value of RESD is very small, that is, 0.359 . The maximum value of financial agglomeration is 0.793 , with a minimum value of 0.015 and an average value of 0.196 . This reflects that there exist remarkable differences in the degree of financial agglomeration among various provinces, and the level of financial agglomeration in China is comparatively low in general. The average value of energy efficiency is 0.657 , with a standard deviation of 0.336 , which demonstrates that the energy efficiency levels of different regions are quite different. In addition, the standard deviation of EPU is 0.523 , meaning that China's EPU index fluctuates greatly from 2009 to 2019.

4.2. Correlation Analysis and Multicollinearity Test. Table 5 presents the results of correlation and multicollinearity analysis. There is a significant correlation between FA and RESD, suggesting that financial agglomeration plays a considerable role in the process of sustainable economic development. Financial agglomeration indeed imposes a positive impact on energy efficiency, which furnishes preliminary evidence for hypothesis 2 . The correlation analysis results are basically consistent with the prior theoretical expectations. Furthermore, the variance inflation factors (VIFs) are less than 10, further stating that there is no multicollinearity between variables.

4.3. Regression Analysis. For the sake of being unaffected by spurious regression and maintaining the reliability of regression results, we first conduct a unit root test before regression. Unit root testing methods contain Im, Pesaran and Shin (IPS), Phillips-Perron test (PP), and augmented Dickey-Fuller test (ADF), etc. This study adopts these unit root testing methods and finds that all variables are stationary at the significance level of 5\%, and thus the original hypothesis of the unit root of these variables could be rejected. The results of the Hausman test indicate that a fixed-effect model should be selected to control the influence of time differences on regression analysis. Meanwhile, in order to control the influence of individual (provincial) differences on regression, the individual-time bidirectional fixed effect model is ultimately employed for panel regression. Additionally, the present study employs bootstrap methods in virtue of the PROCESS program to verify the mediation effect, and variable substitution techniques and GMM regression are executed to test the robustness of the results and to deal with endogenous issues.

The corresponding regression results of equations (15)-(19) are summarized in Table 6. When other confounding factors are controlled, the impact of financial agglomeration on RESD is remarkably positive at the $1 \%$ level, representing that financial agglomeration significantly speeds up the sustainable development of China's regional economy. Therefore, hypothesis 1 is confirmed. Then, a 
TABle 3: Measurement of control variables.

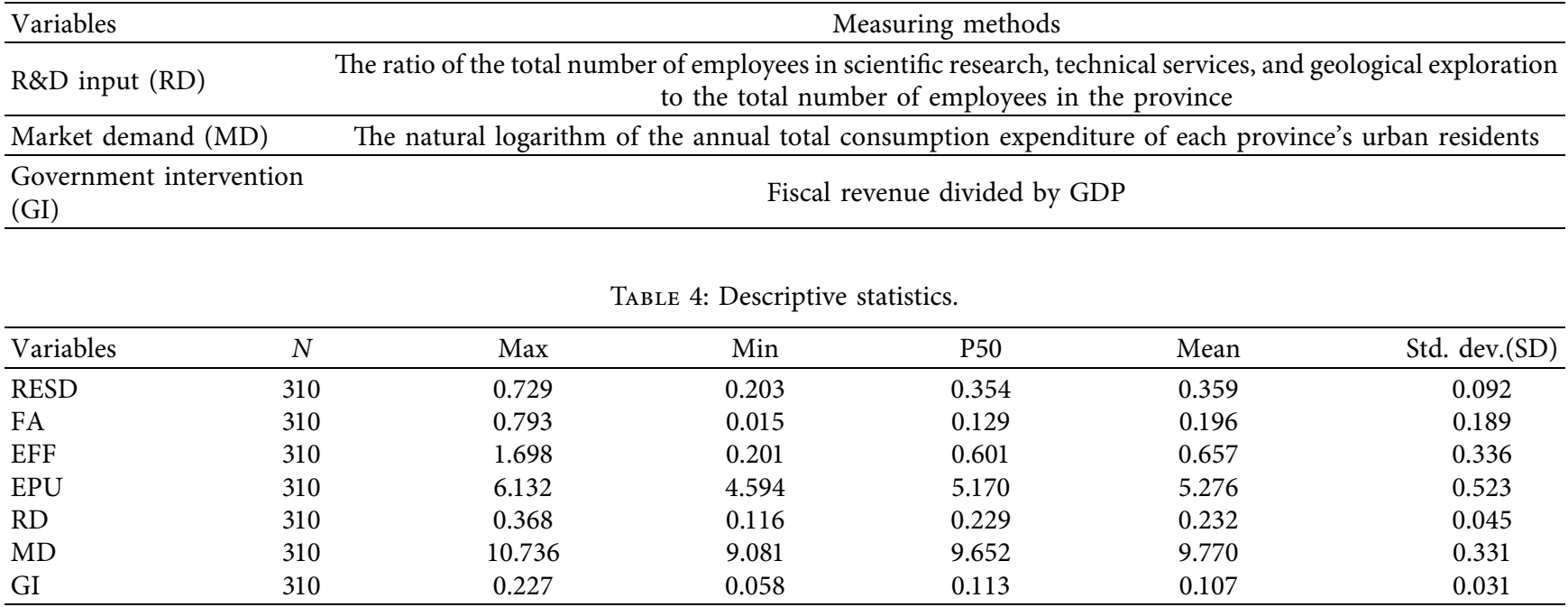

TABLE 5: Correlation between variables and multicollinearity test.

\begin{tabular}{|c|c|c|c|c|c|c|c|c|}
\hline Variables & RESD & FA & EFF & EPU & $\mathrm{RD}$ & MD & GI & VIF \\
\hline RESD & 1 & & & & & & & \\
\hline FA & $0.409^{* *}$ & 1 & & & & & & 5.952 \\
\hline EFF & $0.453^{* *}$ & $0.324^{* *}$ & 1 & & & & & 6.105 \\
\hline EPU & $0.246^{* *}$ & 0.088 & $0.160^{* *}$ & 1 & & & & 2.207 \\
\hline $\mathrm{RD}$ & $0.359^{* *}$ & $0.291^{* *}$ & $0.328^{* *}$ & 0.014 & 1 & & & 2.035 \\
\hline $\mathrm{MD}$ & $0.305^{* *}$ & $0.321^{* *}$ & $0.204^{* *}$ & $0.274^{* *}$ & $0.139^{* *}$ & 1 & & 5.110 \\
\hline GI & $0.284^{* *}$ & $0.237^{*}$ & $0.245^{* *}$ & 0.111 & $0.178^{* *}$ & $0.248^{* *}$ & 1 & 4.891 \\
\hline
\end{tabular}

Note: ${ }^{*} p<0.05$ and ${ }^{* *} p<0.01$

TABLE 6: Regression results.

\begin{tabular}{|c|c|c|c|c|c|}
\hline Variables & $\begin{array}{c}(1) \\
\text { EFF }\end{array}$ & $\begin{array}{c}(2) \\
\text { RESD }\end{array}$ & $\begin{array}{c}(3) \\
\text { RESD }\end{array}$ & $\begin{array}{c}(4) \\
\text { EFF }\end{array}$ & $\begin{array}{c}(5) \\
\mathrm{EFF}\end{array}$ \\
\hline $\mathrm{RD}$ & $\begin{array}{c}0.010 \\
(0.276) \\
\end{array}$ & $\begin{array}{l}0.033^{*} \\
(1.652) \\
\end{array}$ & $\begin{array}{l}0.031^{*} \\
(1.649)\end{array}$ & $\begin{array}{c}0.024 \\
(0.414) \\
\end{array}$ & $\begin{array}{c}0.033 \\
(0.257) \\
\end{array}$ \\
\hline $\mathrm{MD}$ & $\begin{array}{c}0.170^{* * *} \\
(3.800)\end{array}$ & $\begin{array}{c}0.359^{* * *} \\
(14.221) \\
\end{array}$ & $\begin{array}{c}0.328^{* * *} \\
(13.335)\end{array}$ & $\begin{array}{c}0.360^{* * *} \\
(7.390)\end{array}$ & $\begin{array}{c}0.372^{* * *} \\
(7.843)\end{array}$ \\
\hline GI & $\begin{array}{c}0.026 \\
(0.711) \\
\end{array}$ & $\begin{array}{c}-0.116^{* *} \\
(-2.960)\end{array}$ & $\begin{array}{c}-0.120^{* *} \\
(-3.252)\end{array}$ & $\begin{array}{l}-0.116^{*} \\
(-1.735)\end{array}$ & $\begin{array}{l}-0.132^{*} \\
(-2.027)\end{array}$ \\
\hline FA & $\begin{array}{c}0.315^{* * *} \\
(4.619)\end{array}$ & $\begin{array}{c}0.303^{* * *} \\
(7.063)\end{array}$ & & $\begin{array}{l}0.176^{* *} \\
(2.729)\end{array}$ & $\begin{array}{l}0.135^{*} \\
(2.051)\end{array}$ \\
\hline $\mathrm{EFF}$ & & & $\begin{array}{c}0.184^{* * *} \\
(5.514) \\
\end{array}$ & & \\
\hline EPU & & & & $\begin{array}{l}-0.050^{*} \\
(-1.985) \\
\end{array}$ & $\begin{array}{c}-0.056^{*} \\
(-1.830)\end{array}$ \\
\hline $\mathrm{FA} \times \mathrm{EPU}$ & & & & & $\begin{array}{c}-0.078^{* * *} \\
(-2.952)\end{array}$ \\
\hline Constant & $\begin{array}{c}-0.226^{* * *} \\
(-3.898) \\
\end{array}$ & $\begin{array}{c}-0.602^{* * *} \\
(-10.145) \\
\end{array}$ & $\begin{array}{c}-0.618^{* * *} \\
(-10.972) \\
\end{array}$ & $\begin{array}{c}0.624^{* * *} \\
(5.875)\end{array}$ & $\begin{array}{c}0.658^{* * *} \\
(6.344)\end{array}$ \\
\hline Individual & Yes & Yes & Yes & Yes & Yes \\
\hline Year & Yes & Yes & Yes & No & No \\
\hline Observations & 310 & 310 & 310 & 310 & 310 \\
\hline Adjusted $R^{2}$ & 0.846 & 0.951 & 0.956 & 0.886 & 0.892 \\
\hline
\end{tabular}

Note: ${ }^{*},{ }^{* *}$, and ${ }^{* * *}$ indicate the significance level is $10 \%, 5 \%$, and $1 \%$, respectively. 
stepwise regression method is used to determine the mediating effect of energy efficiency. Model 1 reveals that financial agglomeration exhibits a statistically positive influence on energy efficiency at the 1\% level, illustrating that financial agglomeration acts as the determinant for the improvement of energy efficiency. Hypothesis 2 is thus supported. It can be seen from model 3 that, at $1 \%$ level, energy efficiency is significantly positively correlated with RESD, but the coefficient of financial agglomeration has reduced but is still significant. This supports hypothesis 3 and suggests that financial agglomeration provides opportunities for the sustainable development of the regional economy by improving energy efficiency. In order to improve the reliability, we further bootstrapped with 5000 in the study to produce bias-corrected confidence intervals of yield $95 \%$ to verify the mediation effect. The result demonstrated that the mediating effect of energy efficiency was significant with a 95\% confidence interval excluding zero (index $=0.0289$ and $\mathrm{CI}=(0.0117,0.0528))$. Consequently, the mediating effect of energy efficiency is statistically significant.

Model 6 of Table 6 introduces the interaction term between economic policy uncertainty and financial agglomeration to test hypothesis 4 . Since controlling annual fixed effects has alleviated the impact of national macroeconomic fluctuations, and the coexistence of annual fixed effects and EPU would lead to multicollinearity. Model 4 and model 5 cancel the control of the annual fixed effects. It is worth noting that the required variables are standardized to further avoid multicollinearity. The coefficient of FA $\times \mathrm{EPU}$ is -0.078 , which is significant at $1 \%$ level, stating that economic policy uncertainty negatively moderates the relationship between financial agglomeration and energy efficiency. Hypothesis 4 is thus supported. The reason for this discovery may be that, in the face of high EPU, rational agents would delay the company's green technology investment due to political tensions, thereby inhibiting the improvement of energy efficiency. Furthermore, high EPU complicates the business environment and management of a company. In a weak regulatory environment, a company's energy efficiency policies would be compromised.

4.4. Robustness Test and Endogenous Issues. To ensure that the conclusions are robust, replacing the independent variable and the mediator is warranted. Congruent with Yuan et al.'s [6] work, this paper adopts the location entropy index to remeasure financial agglomeration. The specific reference formula is as follows:

$$
\mathrm{FA}_{2}=\frac{E_{i, t} / C_{i, t}}{M_{t} / N_{t}}
$$

where $\mathrm{FA}_{2}$ mirrors location entropy index, $i$ represents province, and $t$ is the year. $E_{i, t}$ reflects the number of financial industry employees of $i$ province in $t$ year. $C_{i, t}$ is the number of employees of all industries in $t$ year of province $i$. $M_{t}$ refers to the number of employees in the national financial industry during $t$, and $N_{t}$ means the number of all industries' employees across the country in $t$ year .

The methodology of NDDF is recommended to regauge energy efficiency by following the study of Ye et al. [1]. Firstly, suppose there exist $n=1,2,3, \ldots, N$ decisionmaking units, and each unit is composed of three inputs, namely, labor input $(X)$, energy input $(Y)$, and capital input $(Z)$, and two outputs: desirable output $(O)$ and undesirable output $(T)$. Meanwhile, the directional vector $f=(-Z,-X$, $-Y, O,-T)^{T}$ and weight vector $W=(1 / 9,1 / 9,1 / 9,1 / 3,1 / 3)^{T}$ are developed, respectively. Then, the linear programming is expressed as

$$
\begin{aligned}
\vec{D}=(Z, X, Y, & O, T ; f)=\max \left(W_{Z} B_{Z}+W_{X} B_{X}+W_{Y} B_{Y}+W_{O} B_{O}+W_{T} B_{T}\right) \\
\text { s.t. } & \sum_{n=1}^{N} v_{n} Z_{n} \leq Z-B_{Z} f_{Z} \\
& \sum_{n=1}^{N} v_{n} X_{n} \leq X-B_{X} f_{X} \\
& \sum_{n=1}^{N} v_{n} Y_{n} \leq Y-B_{Y} f_{Y} \\
& \sum_{n=1}^{N} v_{n} O_{n} \geq O+B_{O} f_{O} \\
& \sum_{n=1}^{N} v_{n} T_{n}=T-B_{T} f_{T} \\
& v_{n} \geq 0, n=1,2, \ldots, N \text { and } B_{Z}, B_{X}, B_{Y}, B_{O}, B_{T} \geq 0 .
\end{aligned}
$$


TABLE 7: Robustness test.

\begin{tabular}{|c|c|c|c|c|c|}
\hline Variables & $\begin{array}{c}(1) \\
\text { EFF2 }\end{array}$ & $\begin{array}{c}(2) \\
\text { RESD }\end{array}$ & $\begin{array}{c}(3) \\
\text { RESD }\end{array}$ & $\begin{array}{c}(4) \\
\text { EFF2 }\end{array}$ & $\begin{array}{c}(5) \\
\text { EFF2 }\end{array}$ \\
\hline $\mathrm{RD}$ & $\begin{array}{c}0.001 \\
(0.028) \\
\end{array}$ & $\begin{array}{c}0.027 \\
(0.198) \\
\end{array}$ & $\begin{array}{l}0.026^{*} \\
(2.125) \\
\end{array}$ & $\begin{array}{c}0.037 \\
(0.228) \\
\end{array}$ & $\begin{array}{l}0.051^{*} \\
(1.732)\end{array}$ \\
\hline MD & $\begin{array}{c}0.173^{* * *} \\
(3.797)\end{array}$ & $\begin{array}{c}0.373^{* * *} \\
(13.679)\end{array}$ & $\begin{array}{c}0.334^{* * *} \\
(12.706)\end{array}$ & $\begin{array}{c}0.353^{* * *} \\
(7.114)\end{array}$ & $\begin{array}{c}0.363^{* * *} \\
(7.616)\end{array}$ \\
\hline GI & $\begin{array}{c}0.013 \\
(0.850)\end{array}$ & $\begin{array}{c}-0.126^{* *} \\
(-3.101)\end{array}$ & $\begin{array}{c}-0.129^{* *} \\
(-3.394)\end{array}$ & $\begin{array}{c}-0.061 \\
(-0.967)\end{array}$ & $\begin{array}{l}-0.089^{*} \\
(-1.403)\end{array}$ \\
\hline $\mathrm{FA}_{2}$ & $\begin{array}{l}0.202^{* *} \\
(2.660) \\
\end{array}$ & $\begin{array}{c}0.220^{* * *} \\
(4.847)\end{array}$ & $\begin{array}{c}0.168^{* * *} \\
(3.898) \\
\end{array}$ & $\begin{array}{c}0.110^{* *} \\
(1.557)\end{array}$ & $\begin{array}{c}0.087 \\
(1.030) \\
\end{array}$ \\
\hline $\mathrm{EFF}_{2}$ & & & $\begin{array}{c}0.211^{* * *} \\
(6.269)\end{array}$ & & \\
\hline EPU & & & & $\begin{array}{c}-0.049 \\
(-1.533) \\
\end{array}$ & $\begin{array}{c}-0.058^{*} \\
(-1.886) \\
\end{array}$ \\
\hline $\mathrm{FA}_{2} \times \mathrm{EPU}$ & & & & & $\begin{array}{c}-0.094^{* * *} \\
(-2.828)\end{array}$ \\
\hline Constant & $\begin{array}{c}-0.133^{* * *} \\
(-2.971)\end{array}$ & $\begin{array}{c}-0.563^{* * *} \\
(-7.892) \\
\end{array}$ & $\begin{array}{c}-0.588^{* * *} \\
(-8.827) \\
\end{array}$ & $\begin{array}{c}0.636^{* * *} \\
(5.774)\end{array}$ & $\begin{array}{c}0.650^{* * *} \\
(6.152)\end{array}$ \\
\hline Individual & Yes & Yes & Yes & Yes & Yes \\
\hline Year & Yes & Yes & Yes & No & No \\
\hline Observations & 310 & 310 & 310 & 310 & 310 \\
\hline Adjusted $R^{2}$ & 0.850 & 0.947 & 0.954 & 0.883 & 0.893 \\
\hline
\end{tabular}

Note: ${ }^{*},{ }^{* *}$, and ${ }^{* * *}$ indicate the significance level is $10 \%, 5 \%$, and $1 \%$, respectively.

Assume that the optimal solution of equation (14) is $B_{n}^{*}=\left(B_{n Z}^{*}, B_{n X}^{*}, B_{n Y}^{*}, B_{n O}^{*}, B_{n T}^{*}\right)^{T}$. Then, the energy efficiency index can be computed according to equation (15):

$$
\begin{aligned}
\mathrm{EFF}_{2}= & \frac{1}{4}\left[\frac{O_{n} / Z_{n}}{\left(O_{n}+B_{n O}^{*} O_{n}\right) /\left(Z_{n}-B_{n Z}^{*} Z_{n}\right)}+\frac{O_{n} / X_{n}}{\left(O_{n}+B_{n O}^{*} O_{n}\right) /\left(X_{n}-B_{n X}^{*} X_{n}\right)}\right. \\
& \left.+\frac{O_{n} / Y_{n}}{\left(O_{n}+B_{n O}^{*} O_{n}\right) /\left(Y_{n}-B_{n Y}^{*} Y_{n}\right)}+\frac{O_{n} / T_{n}}{\left(O_{n}+B_{n O}^{*} O_{n}\right) /\left(T_{n}-B_{n T}^{*} T_{n}\right)}\right] \\
= & \frac{1}{4}\left[\frac{\left(1-B_{n Z}^{*}\right)+\left(1-B_{n X}^{*}\right)+\left(1-B_{n Y}^{*}\right)+\left(1-B_{n T}^{*}\right)}{\left(1+B_{n O}^{*}\right)}\right] \\
= & \frac{1-(1 / 4)\left(B_{n Z}^{*}+B_{n X}^{*}+B_{n Y}^{*}+B_{n T}^{*}\right)}{1+B_{n O}^{*}} .
\end{aligned}
$$

The value range of $\mathrm{EFF}_{2}$ is between 0 and 1 , and the higher the $\mathrm{EFF}_{2}$ value, the higher the level of energy efficiency. For capital input, the perpetual inventory means is employed to calculate each province's capital stock. Energy consumption is described as the product of each province's GDP and energy intensity because China does not make data related to energy sources such as coal and petroleum mandatory. For the sake of simplicity, the paper only takes gross regional product as the measure of desirable output. We construct a labor input index following the disclosure of the number of employees in each province at the end of the year. It is worth noting that, since industrial $\mathrm{SO}_{2}$ emissions occupy an important position in pollutant emissions, the present article uses provincial $\mathrm{SO}_{2}$ emissions to measure undesirable output.
Subsequently, Table 7 details the results of the robustness test after the substitution of the independent variable and the mediator. The empirical outcomes in Table 7 highlight that the key coefficients remain basically unchanged, indicating that the research results are robust.

In addition, two key sources of endogeny are the omission of variables and bidirectional causality. Provinces with high levels of sustainable economic development have sound financial systems or high levels of financial agglomeration, and such reverse causality may lead to deviation of the results. Therefore, IV-GMM regression, which can produce efficient estimates of coefficients as well as the consistent estimates of standard errors, is utilized to solve the potential endogeneity problem [53]. IV-GMM 
TABLE 8: Endogeneity check.

\begin{tabular}{lcc}
\hline Variables & First stage & $\begin{array}{c}\text { Second stage } \\
\text { RESD }\end{array}$ \\
\hline IV $\mathrm{F}_{1}$ & $0.254^{* * *}(4.743)$ & $0.261^{* * *}(5.093)$ \\
$\mathrm{FA}$ & & $0.140^{* * *}(4.124)$ \\
$\mathrm{RD}$ & $0.163^{* * *}(5.878)$ & $0.276^{* * *}(6.345)$ \\
$\mathrm{MD}$ & $0.016(0.461)$ & $0.034(0.504)$ \\
$\mathrm{GI}$ & $-0.042(-0.629)$ & Yes \\
Individual & Yes & Yes \\
Year & Yes & 310 \\
Observations & 310 & 52.89 \\
F statistic & & 1.736 \\
Hansen J statistic & & \\
\hline
\end{tabular}

Note: ${ }^{*},{ }^{* *}$, and ${ }^{* * *}$ indicate the significance level is $10 \%, 5 \%$, and $1 \%$, respectively.

estimation needs to find instrumental variables that are highly related to financial agglomeration but not correlated with RESD. Thus, we use the difference between the FA value of a province in the previous year and the average FA value of the local region (i.e., the eastern, central, or western region where the province is located) as an instrumental variable $\left(\mathrm{IV}_{1}\right)$.

The regression results of IV-GMM are reported in Table 8 . There is a remarkable positive correlation between financial agglomeration and the instrumental variable, and financial agglomeration has a significant positive influence on RESD, which manifests that the main conclusion is robust. In addition, we offer statistical data, Hansen J statistics, which is employed to test overidentification of the tools used in the first stage. It is not statistically significant at any acceptable level, suggesting that the instrumental variable used is valid. Therefore, the paper better verifies the main hypothesis by adopting the IV-GMM method.

\section{Conclusions}

How to facilitate the sustainable development of Chinese cities under the background of increasingly intensified resource and environmental constraints and intensified macroeconomic volatility is a major issue that needs to be resolved urgently by authorities and academia. The sustainable development of economy is an important cornerstone of urban sustainability. Due to the economic, technological, and ecological effects of financial agglomeration, an attempt was developed to demonstrate that one important determinant of the sustainable development of a regional economy was financial agglomeration, using panel data of 29 provinces in China from 2009 to 2019. Meanwhile, by incorporating energy efficiency and economic policy uncertainty into the theoretical framework separately, the present article tried to shed light on the possible mechanism and economic policy scenarios that financial agglomeration affected the regional economy's sustainable development. Several major findings were obtained by adopting the individual-time bidirectional fixed-effect model and performing a robustness test.

First, financial agglomeration exhibited a positive effect on the sustainable development of the regional economy through economic effect, technological effect, and ecological effect, suggesting that the higher the degree of regional financial agglomeration, the higher the level of sustainable development of the Chinese regional economy. The result corroborated the intuition that financial agglomeration not only enabled companies to obtain economies of scale [6] but also ameliorated the corporate innovation environment and increased the proportion of green output by replacing outdated technology with new ones [5]. Second, financial agglomeration was conspicuous positive with energy efficiency, and energy efficiency had mediated the relationship between financial agglomeration and the sustainable development of a regional economy. This endorsed Qu et al.'s [10] narrative that financial agglomeration relied on innovation-driving effect, structural adjustment effect, and information spillover effect to promote energy efficiency. The results were also in line with the logic that energy efficiency not only was the prerequisite for economic growth and economic restructuring [36] but also was directly related to carbon emissions and environmental protection [54, 55]. Third, economic policy uncertainty acts as a remarkable moderating variable in the proceeding of evaluating the influence of financial agglomeration on energy efficiency, that is, when economic policy uncertainty escalates, financial agglomeration begins to exert a weak positive impact on energy efficiency. This may be because, as economic policy uncertainty increases, corporate agency conflicts have intensified and energy-saving technologies have been suppressed [15].

5.1. Management Implications. Based on the discussion of main conclusions, countermeasures in management for facilitating the sustainable development of China's regional economy were summarized as follows:

Firstly, authorities ought to recognize that raising the level of financial agglomeration remains a key option to balance economic growth and environmental quality. In practice, in order to encourage the accumulation of financial capital and financial talents and accelerate financial integration, policymakers must publish steadfast countermeasures, such as compensating policy shortcomings, introducing financial elements, and consolidating physical carriers. Governments should assist local organizations in efforts to establish financial agglomeration centers 
commensurate with the development characteristics and geographic location of the city and thus build a national and gradient financial center network with the advantageous financial centers as the leading and multilevel financial centers as complementary. Secondly, enacting stringent measures to improve energy efficiency is regarded as another priority since it is not comprehensive to solely rely on the effect of financial agglomeration to impel sustainable economic development. The improvement of energy efficiency would yield a double dividend, bringing economic and environmental benefits at the same time to avoid the vicious circle. Thus, China should vigorously promote the reform of energy production and utilization mode, constantly revise the policy system, and strive to achieve the comprehensive, coordinated, and sustainable development of energy, economy, society, and ecology. Finally, Chinese authorities are supposed to maintain the stability and continuity of economic policies because there exists a suppression of economic policy uncertainty on the relation between financial agglomeration and regional energy efficiency. Appropriate measures related to financial agglomeration would be formulated based on the comprehensive identification and assessment of local economic policy uncertainties. In order to maintain the stability of city's economy, regulatory authorities should try to avoid issuing short-term economic policies when announcing economic policies. Especially in the context of intensified resource constraints and increasing downward pressure on the economy, the formulation of economic policies should keep the goals of economic growth and energy conservation and emission reduction unchanged.

5.2. Limitations and Further Research. As with other scientific studies, this paper is subject to certain conditions. First, a caveat of the study was that the research results cannot be simply extrapolated to other cases because this study only selected sample data from China and did not include samples from developed countries or other relatively backward regions for comparison. Hence, future research should endeavor to overcome the limitations of samples to obtain more precise and comparable conclusions. Secondly, according to the principle of data availability, the economic policy uncertainty index used in the present article belongs to the national level rather than the provincial level, which may cause deviation in regional data analysis. Then, it is plausible that subsequent research attempts to evaluate the economic policy uncertainty index of each province in China and further reinvestigates the interaction between EPU and financial agglomeration. Lastly, we call for more indepth quantitative or qualitative research on institutional factors, economic opening, or bureaucratic factors to explore divergent antecedents of the sustainable development of China's regional economy.

\section{Data Availability}

The data supporting the results of this study are available from the corresponding author upon request.

\section{Conflicts of Interest}

The authors declare no conflicts of interest.

\section{Acknowledgments}

The authors acknowledge the support of the Project of the Countermeasures of Innovation and Entrepreneurship Education for College Students in Shaanxi (2016ZD06).

\section{References}

[1] C. Ye, C. Sun, and L. Chen, "New evidence for the impact of financial agglomeration on urbanization from a spatial econometrics analysis," Journal of Cleaner Production, vol. 200, pp. 65-73, 2018.

[2] J. L. Ruiz, "Financial development, institutional investors, and economic growth," International Review of Economics \& Finance, vol. 54, pp. 218-224, 2017.

[3] A. M. Omer, "Energy, environment and sustainable development," Renewable and Sustainable Energy Reviews, vol. 12, no. 9, pp. 2265-2300, 2008.

[4] D. Durusu-Ciftci, M. S. Ispir, and H. Yetkiner, "Financial development and economic growth: some theory and more evidence," Journal of Policy Modeling, vol. 39, no. 2, pp. 290-306, 2017.

[5] H. Yuan, T. Zhang, Y. Feng, Y. Liu, and X. Ye, "Does financial agglomeration promote the green development in China? A spatial spillover perspective," Journal of Cleaner Production, vol. 237, Article ID 117808, 2019.

[6] H. Yuan, Y. Feng, J. Lee, H. Liu, and R. Li, "The spatial threshold effect and its regional boundary of financial agglomeration on green development: a case study in China," Journal of Cleaner Production, vol. 244, Article ID 118670, 2020.

[7] F. J. Buera, J. P. Kaboski, and Y. Shin, "Finance and development: a tale of two sectors," American Economic Review, vol. 101, no. 5, pp. 1964-2002, 2011.

[8] S. Tadesse, "Financial architecture and economic performance: international evidence," Journal of Financial Intermediation, vol. 11, no. 4, pp. 429-454, 2002.

[9] M. Peneder, "Industrial structure and aggregate growth," Structural Change and Economic Dynamics, vol. 14, no. 4, pp. 427-448, 2003.

[10] C. Qu, J. Shao, and Z. Shi, "Does financial agglomeration promote the increase of energy efficiency in China?" Energy Policy, vol. 146, Article ID 111810, 2020.

[11] F. Rubio, C. Llopis-Albert, F. Valero, and A. J. Besa, "Sustainability and optimization in the automotive sector for adaptation to government vehicle pollutant emission regulations," Journal of Business Research, vol. 112, pp. 561-566, 2020.

[12] W. Yang and L. Li, "Energy efficiency, ownership structure, and sustainable development: evidence from China," Sustainability, vol. 9, no. 6, p. 912, 2017.

[13] R. Ayres, H. Turton, and T. Casten, "Energy efficiency, sustainability and economic growth," Energy, vol. 32, no. 5, pp. 634-648, 2007.

[14] S. S. Mirza and T. Ahsan, “Corporates' strategic responses to economic policy uncertainty in China," Business Strategy and the Environment, vol. 29, no. 2, pp. 375-389, 2020.

[15] V. Ongsakul, S. Treepongkaruna, P. Jiraporn, and A. Uyar, "Do firms adjust corporate governance in response to 
economic policy uncertainty? Evidence from board size," Finance Research Letters, vol. 39, Article ID 101613, 2021.

[16] K. Yung and A. Root, "Policy uncertainty and earnings management: international evidence," Journal of Business Research, vol. 100, pp. 255-267, 2019.

[17] Z. Xu, "Economic policy uncertainty, cost of capital, and corporate innovation," Journal of Banking \& Finance, vol. 111, Article ID 105698, 2019.

[18] F. F. Adedoyin, S. Nathaniel, and N. Adeleye, "An investigation into the anthropogenic nexus among consumption of energy, tourism, and economic growth: do economic policy uncertainties matter?" Environmental Science and Pollution Research, vol. 28, no. 3, pp. 2835-2847, 2021.

[19] L. Cheng, S. Zhang, X. Lou, Y. Yang, and W. Jia, "The penetration of new generation information technology and sustainable development of regional economy in Chinamoderation effect of institutional environment," Sustainability, vol. 13, no. 3, p. 1163, 2021.

[20] R. Danish, R. Ulucak, and S. U. D. Khan, "Relationship between energy intensity and $\mathrm{CO}_{2}$ emissions: does economic policy matter?" Sustainable Development, vol. 28, no. 5, pp. 1457-1464, 2020.

[21] J. Corpataux, O. Crevoisier, and T. Theurillat, "The expansion of the finance industry and its impact on the economy: a territorial approach based on Swiss pension funds," Economic Geography, vol. 85, no. 3, pp. 313-334, 2009.

[22] R. E. Baldwin, P. Martin, and G. I. P. Ottaviano, "Global income divergence, trade, and industrialization: the geography of growth take-offs," Journal of Economic Growth, vol. 6, no. 1, pp. 5-37, 2001.

[23] K. Karltorp, S. Guo, and B. A. Sandén, "Handling financial resource mobilisation in technological innovation systemsthe case of Chinese wind power," Journal of Cleaner Production, vol. 142, no. 4, pp. 3872-3882, 2017.

[24] D. B. Audretsch and M. P. Feldman, "R\&D spillovers and the geography of innovation and production," American Economic Review, vol. 86, no. 3, pp. 630-640, 1996.

[25] J. Fu and Y. Geng, "Public participation, regulatory compliance and green development in China based on provincial panel data," Journal of Cleaner Production, vol. 230, pp. 1344-1353, 2019.

[26] E. Kemp-Benedict, "Investing in a green transition," Ecological Economics, vol. 153, pp. 218-236, 2018.

[27] A. Nisar, M. Palacios, and M. Grijalvo, "Open organizational structures: a new framework for the energy industry," Journal of Business Research, vol. 69, no. 11, pp. 5175-5179, 2016.

[28] J. M. Simkoff, F. Lejarza, M. T. Kelley, C. Tsay, and M. Baldea, "Process control and energy efficiency," Annual Review of Chemical and Biomolecular Engineering, vol. 11, no. 1, pp. 423-445, 2020.

[29] Z. Cheng, J. Liu, L. Li, and X. Gu, "Research on meta-frontier total-factor energy efficiency and its spatial convergence in Chinese provinces," Energy Economics, vol. 86, Article ID 104702, 2020.

[30] B. Yu, "Industrial structure, technological innovation, and total-factor energy efficiency in China," Environmental Science and Pollution Research, vol. 27, no. 8, pp. 8371-8385, 2020.

[31] F. Pan and B. Yang, "Financial development and the geographies of startup cities: evidence from China," Small Business Economics, vol. 52, no. 3, pp. 743-758, 2019.

[32] P. Garrone, L. Grilli, and B. Mrkajic, "The role of institutional pressures in the introduction of energy-efficiency innovations," Business Strategy and the Environment, vol. 27, no. 8, pp. 1245-1257, 2018.
[33] N. Hanley, P. G. Mcgregor, J. K. Swales, and K. Turner, "Do increases in energy efficiency improve environmental quality and sustainability?" Ecological Economics, vol. 68, no. 3, pp. 692-709, 2009.

[34] F. C. Ozbugday and B. C. Erbas, "How effective are energy efficiency and renewable energy in curbing $\mathrm{CO}_{2}$ emissions in the long run? A heterogeneous panel data analysis," Energy, vol. 82, pp. 734-745, 2015.

[35] I. Michele and T. D. Ketterer, "Energy efficiency gains from importing intermediate inputs: firm-level evidence from Indonesia," Journal of Development Economics, vol. 135, pp. 117-141, 2018.

[36] C. Bataille and N. Melton, "Energy efficiency and economic growth: a retrospective CGE analysis for Canada from 2002 to 2012,” Energy Economics, vol. 64, pp. 118-130, 2017.

[37] Y. Zhou, M. Ma, F. Kong, K. Wang, and J. Bi, "Capturing the co-benefits of energy efficiency in China - a perspective from the water-energy nexus," Resources, Conservation and Recycling, vol. 132, pp. 93-101, 2018.

[38] I. Dincer and M. A. Rosen, "A worldwide perspective on energy, environment and sustainable development," International Journal of Energy Research, vol. 22, no. 15, pp. 1305-1321, 1998.

[39] L. Pástor and P. Veronesi, "Uncertainty about government policy and stock prices," The Journal of Finance, vol. 67, no. 4, pp. 1219-1264, 2012.

[40] H. N. Duong, J. H. Nguyen, M. Nguyen, and S. G. Rhee, "Navigating through economic policy uncertainty: the role of corporate cash holdings," Journal of Corporate Finance, vol. 62, Article ID 101607, 2020.

[41] S. A. Raza, N. Shah, and M. Shahbaz, "Does economic policy uncertainty influence gold prices? Evidence from a nonparametric causality-in-quantiles approach," Resources Policy, vol. 57, pp. 61-68, 2018.

[42] V. Nagar, J. Schoenfeld, and L. Wellman, "The effect of economic policy uncertainty on investor information asymmetry and management disclosures," Journal of Accounting and Economics, vol. 67, no. 1, pp. 36-57, 2019.

[43] E. Magnani and A. Tubb, "Green R\&D, technology spillovers, and market uncertainty: an empirical investigation," Land Economics, vol. 88, no. 4, pp. 685-709, 2012.

[44] A. Markandya, S. Pedroso-Galinato, and D. Streimikiene, "Energy intensity in transition economies: is there convergence towards the EU average?" Energy Economics, vol. 28, no. 1, pp. 121-145, 2006.

[45] G. D. Jacobsen, "Do energy prices influence investment in energy efficiency? Evidence from energy star appliances," Journal of Environmental Economics and Management, vol. 74, pp. 94-106, 2015.

[46] B. Wilson, L. H. Trieu, and B. Bowen, "Energy efficiency trends in Australia," Energy Policy, vol. 22, no. 4, pp. 287-295, 1994.

[47] I. W. H. Parry, D. Evans, and W. E. Oates, "Are energy efficiency standards justified?" Journal of Environmental Economics and Management, vol. 67, no. 2, pp. 104-125, 2014.

[48] L. Cecchini, S. Venanzi, A. Pierri, and M. Chiorri, "Environmental efficiency analysis and estimation of $\mathrm{CO}_{2}$ abatement costs in dairy cattle farms in Umbria (Italy): a SBM-DEA model with undesirable output," Journal of Cleaner Production, vol. 197, pp. 895-907, 2018.

[49] J. Du, L. Liang, and J. Zhu, "A slacks-based measure of superefficiency in data envelopment analysis: a comment," European Journal of Operational Research, vol. 204, no. 3, pp. 694-697, 2010. 
[50] Y. Zhang, W. Wang, L. Liang, D. Wang, X. Cui, and W. Wei, "Spatial-temporal pattern evolution and driving factors of China's energy efficiency under low-carbon economy," The Science of the Total Environment, vol. 739, Article ID 140197, 2020.

[51] S. R. Baker, N. Bloom, and S. J. Davis, "Measuring economic policy uncertainty," Quarterly Journal of Economics, vol. 131, no. 4, pp. 1593-1636, 2016.

[52] R. M. Baron and D. A. Kenny, "The moderator-mediator variable distinction in social psychological research: conceptual, strategic, and statistical considerations," Journal of Personality and Social Psychology, vol. 51, no. 6, pp. 11731182, 1986.

[53] S. Sheikh, "The impact of market competition on the relation between CEO power and firm innovation," Journal of Multinational Financial Management, vol. 44, pp. 36-50, 2018.

[54] S.-Y. Oh, S. Yun, and J.-K. Kim, "Process integration and design for maximizing energy efficiency of a coal-fired power plant integrated with amine-based $\mathrm{CO} 2$ capture process," Applied Energy, vol. 216, pp. 311-322, 2018.

[55] M. Vujanovic, Q. W. Wang, M. Mohsen, N. Duic, and J. Y. Yan, "Recent progress in sustainable energy-efficient technologies and environmental impacts on energy systems," Applied Energy, vol. 283, Article ID 116280, 2021. 